\title{
Letter From the Executive Editor
}

The Journal of Transformative Leadership and Policy Studies (JTLPS), Volume 8.2, proffers a central thematic link focusing on the importance of transformative leadership, community building, and innovation across the systems in both $\mathrm{K}-12$ and higher education. This focus is built upon by each manuscript, and together they coalesce to create a story about the importance of utilizing the resources within each educational community. They serve as a testament for the significance of abandoning a deficit-based mindset and lifting up the strengths of all affiliates within the institution.

Volume 8.2 of JTLPS begins by featuring two Conceptual Analyses. The first, Moving Past Disconnected Hurdles: Empowering Graduate Students to Affect Positive Change Through the Thesis and Dissertation Experience engages readers on issues surrounding the dissertation and thesis process within educational programs, particularly those with a practitioner focus. The authors suggest that the thesis and dissertation focus and process within these programs must be altered to better match the preparation and needs of students who are practitioners within the field of education. The piece further illustrates that for many of the students the thesis and dissertation and its necessitation of strong research skills, including data collection and analysis, and academic writing is disconnected from the complex realities of the classrooms and administrative offices where these students work or will work. The authors conclude the piece by suggesting several pragmatic recommendations for improving the educational thesis and dissertation process as well as suggestions for mentoring and strategic coaching methods.

A second featured conceptual analysis, Beyond the Public-Private Nexus: A Framework for Examining School Partnership Governance in a Blended Capital Reality highlights school-based partnerships and collaborations. The authors emphasize the realities of educational funding in the PK-12 space and introduce a new framework to establish school-based collaborations to fit the current contexts and challenges facing education today. This framework proposes that the existing needs of the education warrant a "blended-capital" approach to school governance underscored by cross-sector collaboration and de-centralization. This piece offers guidance for school leaders, providing insight on how to manage relationships with an innovative variety of allies, who will join in their focus on matters of curriculum, personnel, policy, programming, and providing valuable tools to aid in the transformation of schools.

The third manuscript in Volume 8.2, a reflective essay, written by lifelong educators and practitioners working to transform schools in Guatemala, is presented as a bi-lingual article with both the Spanish and the English versions provided within the volume. The piece focuses on the challenges within the education system in the Western Highlands of Guatemala despite the efforts that have been made to improve the system and foster economic growth and development within the region. The piece highlights the work of the U.S. Agency for International Development (USAID) which has implemented specific educational projects to support the National Ministry of 
Education to foster economic and social growth in education in this area. The authors emphasize the importance of a transformative pedagogical leadership approach, which shifts strategies from a management-oriented system to a mentoring system allowing for all affiliates to thrive within this strength-based leadership environment. Furthermore, additional suggestions are proposed to gain the support of stakeholders, expanding implementation to bilingual and multicultural contexts to maximize the country's potential to improve the quality of education for all students. Practitioners and leaders can use this manuscript evidence of the power of transformative leadership for all members of educational institutions.

The volume also includes an engaging policy brief on the implementation process of a Grow-Your- Own (GYO) model to address the necessity for special education teacher recruitment and retention strategies. The brief touched on this need by highlighting the critical shortage of highly-qualified, well-trained and seasoned teachers within special education programs in California schools. The issue of special education teacher recruitment and retention is presented by the author as a potential equity problem for student success. Utilizing a Leader-Member exchange theory framework as well as personal communications from practitioners, the brief provide rich and detailed reasoning for why GYO models meet these challenges and how implementation of GYO modeling works at the site level.

The volume concludes with two book reviews from recent educational leadership research publications, which collectively describe the experiences of transformative leaders in the field. The first review highlights Transformative Leadership in Education: Equitable and Socially Just Change in an Uncertain and Complex World a critical approach to transformative leadership, provoking leaders across the nation to rise against the inequities within their institutions. The book presents a framework for approaching leadership that is mindful of the nuances, fluidity, and uncertainty of education. The reviewers offer both positive feedback and several key recommendations for future considerations. The second review focuses on Culturally Responsive School Leadership which emphasizes the importance of School and cultural improvement initiatives that transcend surface-level school interactions. This book proffers that educators must not only call out the racism they see around them, but must also take part in a self-reflection which analyzed the ways in which they too perpetuate racism within their institutions. Together, these books, rich with qualitative data as well as theoretically and empirically backed research, serve as tools and inspiration for educational leaders, that through transformational leadership, meaningful, lasting change is both possible and attainable.

The JTLPS and its editorial board wishes to thank the Chancellor's Office of the California State University and the College of Education at California State University, Sacramento for its continued support. We also invite future authors to submit their manuscripts with the understanding that they are accepted for review on a rolling basis.

\section{Porfirio M. Loeza, Ph.D.}

Executive Editor 